\title{
Association of vitamin D receptor polymorphisms and type 1 diabetes susceptibility in children: a meta-analysis
}

\author{
Ozlem Atan Sahin ${ }^{1}$, Damla Goksen ${ }^{2}$, Aysel Ozpinar ${ }^{3}$, Muhittin Serdar ${ }^{3}$ and \\ Huseyin Onay ${ }^{4}$
}

${ }^{1}$ Department of Pediatrics, Acıbadem University School of Medicine, Atasehir, Istanbul, Turkey ${ }^{2}$ Department of Pediatric Endocrinology, Faculty of Medicine, Ege University, Bornova, Izmir, Turkey ${ }^{3}$ Department of Biochemistry, Acıbadem University, School of Medicine, Atasehir, Istanbul, Turkey ${ }^{4}$ Department of Medical Genetics, Faculty of Medicine, Ege University, Bornova, Izmir, Turkey
Correspondence should be addressed to O A Sahin

Email

ozlemnaciyeatansahin@ yahoo.com

\begin{abstract}
Background: There have been studies focused on Fokl, Bsml, Apal and Taql polymorphisms of the vitamin $D$ receptor (VDR) gene and susceptibility to type 1 diabetes mellitus with controversial results.

Methods: This present study is a meta-analysis investigating the association between Fokl, Apal, Taql and Bsml polymorphisms of VDR gene and type 1 DM in children. A literature search was performed using Medline, EMBASE, Cochrane and PubMed. Any study was considered eligible for inclusion if at least one of Fokl, Apal, Taql and Bsml polymorphisms was determined, and outcome was type $1 \mathrm{DM}$ at pediatric age. Results: A total of 9 studies comprising 1053 patients and 1017 controls met the study inclusion criteria. The pooled odds ratios (ORs) of the Fokl, Apal, Taql and Bsml polymorphisms were combined and calculated. Forest plots and funnel plots of the OR value distributions were drawn. Our meta-analysis has demonstrated statistically significant associations between DM1 and VDR genotypes, BsmIBB $(P<0.05), B s m I B b$, $(P<0.05)$, Bsmlbb $(P<0.05)$, TaqITT $(P<0.05)$ and Taqltt $(P<0.05)$ in children. Conclusion: The results indicated that BsmIBB, BsmIBb and Taqltt polymorphisms were associated with an increased risk of type 1 DM, whereas Bsmlbb and TaqITT had protective effect for type 1 DM in children.
\end{abstract} Key Words

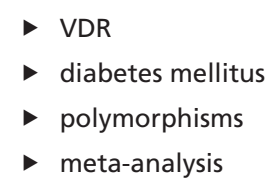

Endocrine Connections (2017) 6, 159-171

\section{Introduction}

Type 1 diabetes (DM1) is a complex disease characterized by the autoimmune destruction of pancreatic $\beta$ cells. Vitamin D is an immune regulatory hormone that exerts its effects through highly polymorphic VDR that belongs to steroid-receptor superfamily, and it is expressed in many cell types such as lymphocytes and antigenpresenting cells (APCs) (1). During the last decade, VDR gene polymorphisms have been shown to be associated with autoimmune pathologies (2). Vitamin D seems to downregulate type 1 helper (Th-1) cells, by decreasing their proliferation and inhibiting the production of cytokines such as IL- 2 , TNF- $\alpha$ and interferon- $\gamma(3,4)$. For many years, the strongest genetic contribution to DM1 susceptibility had been attributed to the presence of human leukocyte antigen region (HLA) on chromosome $6(5,6)$. Recently, single nucleotide polymorphisms (SNPs) in the VDR gene have been investigated namely FokI $F>f$ (rs10735810), BsmI $B>b$ (rs1544410), ApaI $A>a$

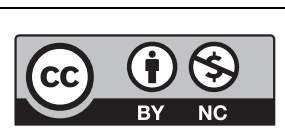

This work is licensed under a Creative Commons Attribution-NonCommercial 4.0 International License. 
(rs7975232) and TaqI t $T>t$ (rs731236). Allele $\mathrm{F}$ of the FokI SNP creates an alternative ATG initiation codon in exon 2 leading to a three amino acid longer VDR protein. The ApaI, BsmI and TaqI polymorphisms take place near the $3^{\prime}$ end of the VDR gene; BsmI and ApaI SNPs are located in intron 8 , and the TaqI is a silent SNP in exon 9. Several studies with small data sets that suggested an association between these SNPs and type 1 DM had inconsistent results $(7,8,9,10)$. These inconclusive results had been attributed to ethnic diversities among populations or due to the environmental factors involved in type $1 \mathrm{DM}$ pathogenesis. Bsm I is strongly linked with 3 poly(A) microsatellite repeat in the $3^{\prime}$ untranslated region, which may influence VDR mRNA stability (11). BsmI, ApaI and TaqI polymorphisms were also designated as polymorphisms without functional effects in several studies $(12,13)$. There are some discrepancies in the literature with small data sets, regarding the relative importance of polymorphisms of VDR genes ApaI, BsmI, FokI and TaqI. In our meta-analysis, we included a total of 9 studies comprising 1053 patients and 1017 controls that indicated statistically significant associations between DM1 and VDR genotypes, BsmIBB $(P<0.05)$, BsmIBb $(P<0.05), B s m I b b(P<0.05)$, TaqITT $(P<0.05)$ and TaqItt $(P<0.05)$ in children. This present meta-analysis involves a large data set to investigate the associations between type 1 DM and VDR gene polymorphisms ApaI, BsmI, FokI and TaqI, accordingly demonstrate more reliable statistical results to rule out genotype-phenotype correlation of type $1 \mathrm{DM}$ in children.

\section{Methods}

\section{Search strategy criteria}

For meta-analysis, all published studies evaluating the associations between type $1 \mathrm{DM}$ and FokI, ApaI, TaqI and BsmI polymorphisms that are investigated in patients diagnosed as DM1 at pediatric age are included. A literature search for the MeSH terms 'type 1 Diabetes mellitus' or 'DM1' was performed by O A, D G and M S Medline, Cochrane and PubMed abstracts were reviewed for relevance. No language and date of study restriction were applied to search strategy. Search to include the eligible studies ended on 05/14/2016. Any study was considered to be eligible for inclusion if it met the following criteria: (1) the publication was an association study of the case control type, (2) at least one of the FokI, ApaI, TaqI and BsmI polymorphism was determined,
(3) the outcome was DM in children and (4) there was at least one unrelated control group.

\section{Data extraction}

Study selection and data extraction were performed independently by three authors (O A, D G and M S) based on a customized database for extraction. For each study, the following information was collected: first author, year and location of the study, average age at the time of diagnosis, ethnicity, number of participants, number of cases and controls and number of the genotypes in cases and controls. The disagreements were resolved between the reviewers by consensus. For quality assessment, six domains were assessed. Those were representativeness of classes, representativeness of the controls, ascertainment of DM1, genotypic examination and association of assessment. The primary outcome considered in the meta-analysis was the association between DM1 and the presence of FokI, ApaI, TaqI or BsmI polymorphism at pediatric age. For the primary analysis and to allow appropriate comparison of all studies, cases and controls were classified based on FokI, ApaI, TaqI and BsmI genotypes.

\section{Statistical analysis}

The odds ratios (OR) with 95\% confidence intervals, representativeness of controls, ascertainment of DM1, ascertainment of controls, genotypic examination and association assessments were done. The primary outcome considered in the meta-analysis was the association between DM1 and the presence of FokI, ApaI, TaqI or BsmI polymorphisms. MedCalc Software Acacialaan 22, 8400 (Ostend, Belgium) was used to perform meta-analysis. The odds ratios (OR) of the genetic polymorphisms were combined and calculated, and the funnel plots were drawn. All of the four studied SNPs (FokI, ApaI, TaqI and $B s m I$ ) were diallelic, and we calculated summary odds ratios incorporating both within- and between-study variation using a random effects model proposed by DerSimonian and Laird (14).

\section{Results}

Our search yielded a total of 50 references. After screening the titles and abstracts, 41 studies were excluded because they were not considered relevant to the study topic, 


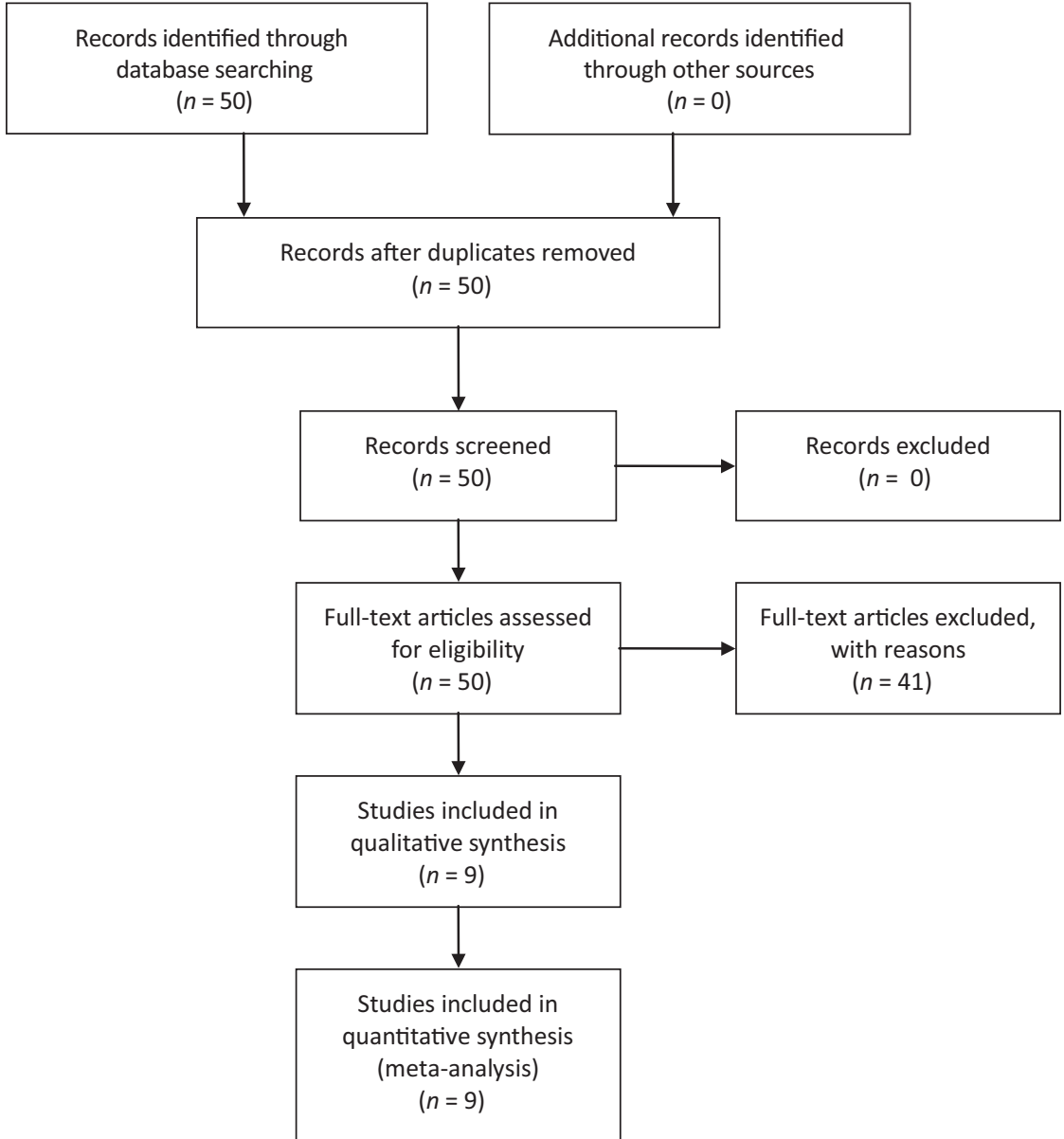

Figure 1

Flow chart for identification and selection of studies.

leaving 9 potentially eligible studies (Fig. 1) $(15,16,17$, $18,19,20,21,22,23)$.

In the 9 published papers included in the metaanalysis, ApaI, BsmI, FokI and TaqI polymorphisms were investigated in pediatric population as case-control studies (Table 1).

Eight studies on the ApaI-type 1 diabetes association recruited 921 cases/patients and 1033 controls, whereas seven studies on the BsmI polymorphism recruited 866 cases and 983 controls. For the FokI polymorphism, five studies included 465 cases and 569 controls, whereas eight studies on the TagI polymorphism included 921 cases and 1033 controls. Individual and pooled odds ratio estimates of four single-nucleotide polymorphisms in the vitamin receptor gene, $P$ values testing Hardy-Weinberg proportion, test for heterogeneity (Tables $2,3,4,5,6,7,8$, 9, 10, 11, 12 and 13) and funnels plots (Figs 2 and 3) are documented for BsmI and TaqI, respectively.

Table 1 Characteristics features of studies included in the meta-analysis of Apal, Bsml, Fokl and Taql polymorphisms in the vitamin $\mathrm{D}$ receptor gene.

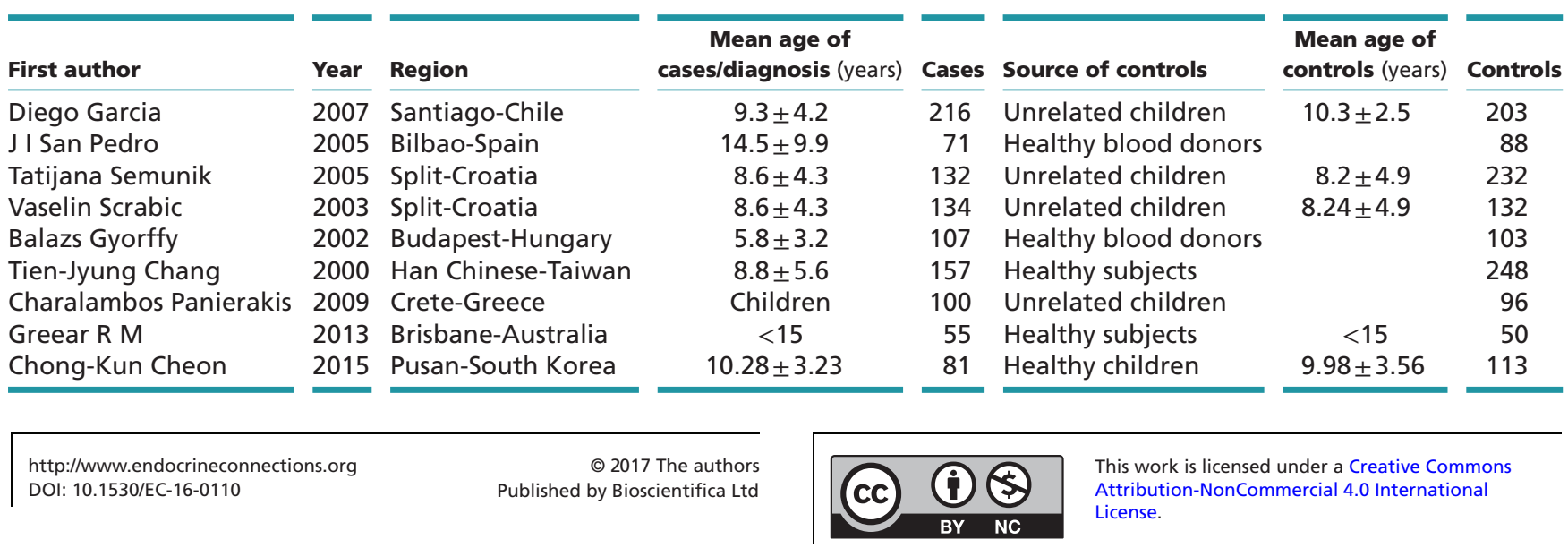


Table $2 P$ values testing Hardy-Weinberg proportion and test for heterogeneity of studies included in the meta-analysis for Apal AA polymorphism respectively.

\begin{tabular}{l}
\hline Study \\
\hline T J Chang 2000 \\
Balazs Gyorffy 2002 \\
Vaselin Scrabic 2003 \\
J J San Pedro 2005 \\
Diego Garcia 2007 \\
C Panierakis 2009 \\
Greear R M 2013 \\
Chung Cheon 2015 \\
Total (fixed effects) \\
Total (random effects) \\
Q \\
DF \\
Significance level \\
$I^{2}$ (inconsistency) \\
$95 \%$ Cl for ${ }^{2}$ \\
\hline
\end{tabular}

\begin{tabular}{c}
\hline Intervention \\
\hline $16 / 157$ \\
$33 / 107$ \\
$66 / 134$ \\
$15 / 71$ \\
$54 / 216$ \\
$23 / 100$ \\
$15 / 55$ \\
$5 / 81$ \\
$227 / 921$ \\
$227 / 921$ \\
16.3471 \\
7 \\
$P=0.0221$ \\
$57.18 \%$ \\
$5.93-80.51$ \\
\hline
\end{tabular}

\begin{tabular}{ccc}
\hline Controls & & Odds ratio \\
\cline { 1 - 1 } $13 / 248$ & & 2.051 \\
$23 / 103$ & & 1.551 \\
$51 / 132$ & 1.542 \\
$28 / 88$ & 0.574 \\
$43 / 203$ & 1.240 \\
$37 / 96$ & 0.476 \\
$12 / 50$ & 1.187 \\
$9 / 113$ & 0.760 \\
$216 / 1033$ & & 1.113 \\
$216 / 1033$ & & 1.081
\end{tabular}

\begin{tabular}{cllll}
\hline $\mathbf{9 5 \%} \mathbf{C l}$ & $\mathbf{z}$ & & $\boldsymbol{P}$ \\
\cline { 1 - 1 } $0.958-4.391$ & & & \\
$0.835-2.881$ & & & \\
$0.947-2.509$ & & & \\
$0.278-1.185$ & & & \\
$0.786-1.957$ & & & \\
$0.256-0.886$ & & & \\
$0.493-2.861$ & & & \\
$0.245-2.359$ & & & \\
$0.893-1.388$ & & 0.954 & \\
$0.755-1.547$ & & 0.425 & \\
& & & \\
\hline
\end{tabular}

Bias indicators: Begg-Mazumdar: Kendall's Tau $=-0.142857 P=0.5484$ (low power); Egger: bias $=-1.369742(95 \% \mathrm{Cl}=-6.646958$ to 3.907474$) P=0.5488$; Harbord-Egger: bias $=-1.179831(92.5 \% \mathrm{Cl}=-5.949539$ to 3.589877$) P=0.6138$.

DF, degree of freedom; Q, heterogeneity in meta analysis.

Of the articles included in the study, investigators of all studies included in the meta-analysis specifically looked for the presence of autoantibodies to diagnose type 1 diabetes and all fulfilled World Health Organization and the American Diabetes Association criteria (24).

Selection of controls varied across studies. Groups of controls included healthy blood donors and unrelated children.

\section{Apal, Bsml, Fokl and Taql polymorphisms and the risk for type 1 diabetes}

For ApaI-AA, the odds ratio ranged from 0.476 to 2.051 (Table 2). The random-effects model yielded a pooled odds ratio of 1.081 (95 percent confidence interval (CI): $0.755-1.547)$. There was indication of heterogeneitiy $(P=0.0221)$.

Table $3 P$ values testing Hardy-Weinberg proportion and test for heterogeneity of studies included in the meta-analysis for Apal Aa polymorphism respectively.

\begin{tabular}{l}
\hline Study \\
\cline { 1 - 2 } T J Chang 2000 \\
Balazs Gyorffy 2002 \\
Vaselin Scrabic 2003 \\
J J San Pedro 2005 \\
Diego Garcia 2007 \\
C Panierakis 2009 \\
Greear R M 2013 \\
Chung Cheon 2015 \\
Total (fixed effects) \\
Total (random effects) \\
Q \\
DF \\
Significance level \\
$P^{2}$ (inconsistency) \\
$95 \%$ Cl for $I^{2}$
\end{tabular}

\begin{tabular}{c}
\hline Intervention \\
\hline $76 / 157$ \\
$45 / 107$ \\
$52 / 134$ \\
$37 / 71$ \\
$115 / 216$ \\
$58 / 100$ \\
$24 / 55$ \\
$32 / 81$ \\
$439 / 921$ \\
$439 / 921$ \\
14.2512 \\
7 \\
$P=0.0469$ \\
$50.88 \%$ \\
$0.00-78.02$
\end{tabular}

\begin{tabular}{c}
\hline Controls \\
\hline $105 / 248$ \\
$54 / 103$ \\
$66 / 132$ \\
$43 / 88$ \\
$125 / 203$ \\
$57 / 96$ \\
$32 / 50$ \\
$34 / 113$ \\
$516 / 1033$ \\
$516 / 1033$ \\
\end{tabular}

\begin{tabular}{c}
\hline Odds ratio \\
\hline 1.278 \\
0.659 \\
0.634 \\
1.139 \\
0.710 \\
0.945 \\
0.435 \\
1.517 \\
0.873 \\
0.866 \\
\end{tabular}

\begin{tabular}{c}
$95 \% \mathbf{C l}$ \\
\hline $0.855-1.910$ \\
$0.382-1.136$ \\
$0.390-1.032$ \\
$0.609-2.129$ \\
$0.481-1.048$ \\
$0.535-1.669$ \\
$0.198-0.956$ \\
$0.833-2.765$ \\
$0.729-1.046$ \\
$0.664-1.131$ \\
\end{tabular}

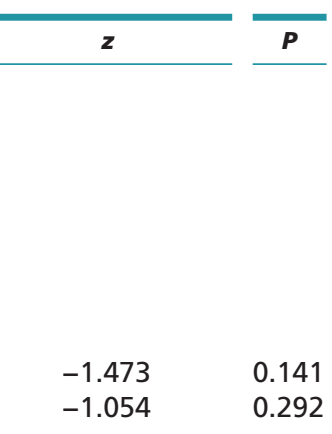

Bias indicators: Begg-Mazumdar: Kendall's Tau $=0 P=0.9049$ (low power); Egger: bias $=-0.928241(95 \% \mathrm{Cl}=-7.113964$ to 5.257482$) P=0.7261$; Harbord-Egger: bias $=-0.806491(92.5 \% \mathrm{Cl}=-6.321591$ to 4.708608$) P=0.7638$.

$\mathrm{DF}$, degree of freedom; $\mathrm{Q}$, heterogeneity in meta analysis.

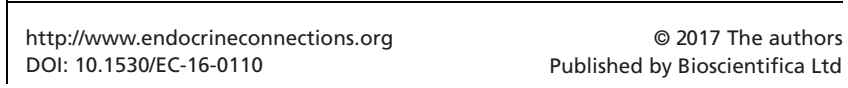


Table $4 P$ values testing Hardy-Weinberg proportion and test for heterogeneity of studies included in the meta-analysis for Apal aa polymorphism respectively.

\begin{tabular}{l}
\hline Study \\
\hline T J Chang 2000 \\
Balazs Gyorffy 2002 \\
Vaselin Scrabic 2003 \\
J J San Pedro 2005 \\
Diego Garcia 2007 \\
C Panierakis 2009 \\
Greear R M 2013 \\
Chung Cheon 2015 \\
Total (fixed effects) \\
Total (random effects) \\
Q \\
DF \\
Significance level \\
$R^{2}$ (inconsistency) \\
$95 \%$ Cl for ${ }^{2}$ \\
\hline
\end{tabular}

\begin{tabular}{ccc}
\hline Intervention & & Controls \\
\cline { 1 - 1 } $65 / 157$ & & $130 / 248$ \\
$27 / 107$ & & $26 / 103$ \\
$16 / 134$ & & $15 / 132$ \\
$19 / 71$ & & $17 / 88$ \\
$44 / 216$ & $35 / 203$ \\
$15 / 100$ & $6 / 96$ \\
$11 / 55$ & & $11 / 50$ \\
$44 / 81$ & & $70 / 113$ \\
$241 / 921$ & & $310 / 1033$ \\
$241 / 921$ & \\
11.2531 & \\
7 & \\
$P=0.1280$ & \\
$37.79 \%$ & \\
$0.00-72.53$ & \\
\hline
\end{tabular}

\begin{tabular}{c}
\hline Odds ratio \\
\hline 0.641 \\
1.000 \\
1.058 \\
1.526 \\
1.228 \\
2.647 \\
0.886 \\
0.731 \\
0.956 \\
1.005
\end{tabular}

\begin{tabular}{ccccc}
\hline $\mathbf{9 5} \% \mathbf{C l}$ & $\boldsymbol{z}$ & $\boldsymbol{P}$ \\
\cline { 1 - 1 } $0.428-0.960$ & & & \\
$0.500-2.238$ & & & \\
$0.724-3.217$ & & & \\
$0.751-2.009$ & & & \\
$0.982-7.139$ & & & \\
$0.346-2.270$ & & & \\
$0.409-1.304$ & & & \\
$0.772-1.182$ & & -0.419 & \\
$0.754-1.339$ & & 0.0349 & 0.972 \\
& & & \\
\hline
\end{tabular}

Bias indicators: Begg-Mazumdar: Kendall's Tau $=0.428571 P=0.1789$ (low power); Egger: bias $=2.766246(95 \% \mathrm{Cl}=-0.351565$ to 5.884058$) P=0.073$; Harbord-Egger: bias $=2.78392(92.5 \% \mathrm{Cl}=-0.118976$ to 5.686817$) P=0.0847$. $\mathrm{DF}$, degree of freedom; Q, heterogeneity in meta analysis.

For ApaI-Aa, the odds ratio ranged from 0.435 to 1.517 (Table 3). The random-effects model yielded a pooled odds ratio of 0.866 (95 percent confidence interval (CI): 0.664-1.131). There was indication of heterogeneity $(P=0.0469)$.

For ApaI-aa, the odds ratio ranged from 0.641 to 2.647 (Table 4). The fixed-effects model yielded a pooled odds ratio of 0.956 (95 percent confidence interval (CI): $0.772-1.182)$. There was indication of homogeneity $(P=0.1280)$. In view of these estimates, there is no evidence that any of the three alleles alone is associated with type 1 diabetes.
For BsmI-BB, the odds ratio ranged from 0.460 to 6.458 (Table 5). The fixed-effects model yielded a pooled odds ratio of 1.397 (95 percent confidence interval (CI): 1.034 1.888, $P=0.030)$. There was indication of homogeneity $(P=0.4531)$.

For BsmI-Bb, the odds ratio ranged from 0.598 to 5.210 (Table 6). The random-effects model yielded a pooled odds ratio of 1.534 (95 percent confidence interval (CI): 1.001-2.350, $P=0.049)$. There was indication of heterogeneity $(P=0.0014)$.

For BsmI-bb, the odds ratio ranged from 0.242 to 1.407 (Table 7). The random-effects model yielded a

Table $5 P$ values testing Hardy-Weinberg proportion and test for heterogeneity of studies included in the meta-analysis for $B s m I B B$ polymorphism, respectively.

\begin{tabular}{|c|c|c|c|}
\hline Study & Intervention & Controls & Odds ratio \\
\hline T J Chang 2000 & 4/157 & $1 / 248$ & 6.458 \\
\hline Balazs Gyorffy 2002 & $17 / 107$ & 19/103 & 0.835 \\
\hline Vaselin Scrabic 2003 & $24 / 134$ & $17 / 132$ & 1.476 \\
\hline J J San Pedro 2005 & $15 / 71$ & $17 / 88$ & 1.119 \\
\hline Diego Garcia 2007 & $21 / 216$ & $14 / 203$ & 1.454 \\
\hline C Panierakis 2009 & $38 / 100$ & 23/96 & 1.945 \\
\hline Chung Cheon 2015 & 0/81 & $1 / 113$ & 0.460 \\
\hline Total (fixed effects) & $119 / 866$ & $92 / 983$ & 1.397 \\
\hline Total (random effects) & $119 / 866$ & $92 / 983$ & 1.386 \\
\hline Q & 5.7387 & & \\
\hline DF & 6 & & \\
\hline Significance level & $P=0.4531$ & & \\
\hline$R^{2}$ (inconsistency) & $0.00 \%$ & & \\
\hline $95 \% \mathrm{Cl}$ for $l^{2}$ & $0.00-69.98$ & & \\
\hline
\end{tabular}

\begin{tabular}{|c|c|c|}
\hline $95 \% \mathrm{Cl}$ & $z$ & $\boldsymbol{P}$ \\
\hline $0.715-58.314$ & & \\
\hline $0.407-1.713$ & & \\
\hline $0.752-2.896$ & & \\
\hline $0.514-2.435$ & & \\
\hline $0.718-2.943$ & & \\
\hline $1.048-3.611$ & & \\
\hline $0.0185-11.440$ & & \\
\hline 1.034-1.888 & 2.174 & 0.030 \\
\hline $1.021-1.880$ & 2.092 & 0.036 \\
\hline
\end{tabular}

Bias indicators: Begg-Mazumdar: Kendall's Tau $=-0.333333 P=0.2389$ (low power); Egger: bias $=0.081309(95 \% \mathrm{Cl}=-2.562044$ to 2.724662$) P=0.94$; Harbord-Egger: bias $=0.057432(92.5 \% \mathrm{Cl}=-2.538737$ to 2.653601$) P=0.9624$

$\mathrm{DF}$, degree of freedom; Q, heterogeneity in meta analysis.

\begin{tabular}{|lr}
\hline http://www.endocrineconnections.org & ○ 2017 The authors \\
DOI: 10.1530/EC-16-0110 & Published by Bioscientifica Ltd
\end{tabular}

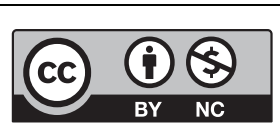

This work is licensed under a Creative Commons Attribution-NonCommercial 4.0 International License. 
Table 6 values testing Hardy-Weinberg proportion and test for heterogeneity of studies included in the meta-analysis for Bsml Bb polymorphism, respectively.

\begin{tabular}{l}
\hline Study \\
\hline Chang 2000 \\
Balazs Gyorffy 2002 \\
Vaselin Scrabic 2003 \\
J J San Pedro 2005 \\
Diego Garcia 2007 \\
C Panierakis 2009 \\
Chung Cheon 2015 \\
Total (fixed effects) \\
Total (random effects) \\
Q \\
DF \\
Significance level \\
R (inconsistency) \\
$95 \%$ Cl for $R^{2}$
\end{tabular}

\begin{tabular}{cccc}
\hline Intervention & & Controls \\
\cline { 1 - 1 } $16 / 157$ & & $16 / 248$ \\
$53 / 107$ & & $44 / 103$ \\
$58 / 134$ & & $74 / 132$ \\
$40 / 71$ & & $44 / 88$ \\
$110 / 216$ & & $74 / 203$ \\
$43 / 100$ & & $23 / 96$ \\
$13 / 81$ & & $4 / 113$ \\
$333 / 866$ & & $279 / 983$ \\
$333 / 866$ & & $279 / 983$ \\
21.6238 & & \\
6 & & \\
$P=0.0014$ & & \\
$72.25 \%$ & & \\
$40.02-87.16$ &
\end{tabular}

\begin{tabular}{c}
\hline Odds ratio \\
\hline 1.645 \\
1.316 \\
0.598 \\
1.290 \\
1.809 \\
2.394 \\
5.210 \\
1.430 \\
1.534 \\
\end{tabular}

\begin{tabular}{|c|c|c|}
\hline $95 \% \mathrm{Cl}$ & $z$ & $\boldsymbol{P}$ \\
\hline $0.798-3.393$ & & \\
\hline $0.764-2.268$ & & \\
\hline $0.368-0.971$ & & \\
\hline $0.688-2.418$ & & \\
\hline $1.224-2.674$ & & \\
\hline $1.296-4.422$ & & \\
\hline $1.632-16.633$ & & \\
\hline $1.160-1.762$ & 3.347 & 0.001 \\
\hline $1.001-2.350$ & 1.966 & 0.049 \\
\hline
\end{tabular}

Bias indicators: Begg-Mazumdar: Kendall's Tau $=-0.333333 P=0.3813$ (low power); Egger: bias $=2.518064(95 \% \mathrm{Cl}=-4.133965$ to 9.170093$) P=0.3752$; Harbord-Egger: bias $=2.595692(92.5 \% \mathrm{Cl}=-3.668787$ to 8.860172$) P=0.3955$.

$\mathrm{DF}$, degree of freedom; Q, heterogeneity in meta analysis.

pooled odds ratio of 0.624 (95 percent confidence interval (CI): $0.418-0.933, P=0.022$ ). There was indication of heterogeneity $(P=0.0075)$.

Forest plots are shown in Fig. 2A, B and C for BsmI $\mathrm{BB}, \mathrm{Bb}$ and $\mathrm{bb}$ alleles, respectively. Individual and pooled odds ratio estimates for the BsmI alleles are represented as squares and diamonds. In view of these estimates, there is evidence that BsmI-Bb or BsmI-bb alone is associated with type 1 diabetes.

For FokI-FF, the odds ratio ranged from 0.485 to 1.636 (Table 8). The fixed-effects model yielded a pooled odds ratio of 1.057 (95 percent confidence interval (CI): 0.817-1.367, $P=0.675)$. There was indication of homogeneity $(P=0.1443)$.

For FokI-Ff, the odds ratio ranged from 0.645 to 1.222 (Table 9). The fixed-effects model yielded a pooled odds ratio of 0.724 (95 percent confidence interval (CI): 0.564$0.929, P=0.011)$. There was indication of homogeneity $(P=0.4324)$.

For FokI-ff, the odds ratio ranged from 0.128 to 2.558 (Table 10). The random-effects model yielded a pooled odds ratio of 1.159 (95 percent confidence interval (CI): $0.573-2.344, P=0.681)$. There was indication of heterogeneity $(P=0.0384)$.

Table $7 \quad P$ values testing Hardy-Weinberg proportion and test for heterogeneity of studies included in the meta-analysis for Bsml bb polymorphism, respectively.

\begin{tabular}{l}
\hline Study \\
\hline T J Chang 2000 \\
Balazs Gyorffy 2002 \\
Vaselin Scrabic 2003 \\
J J San Pedro 2005 \\
Diego Garcia 2007 \\
C Panierakis 2009 \\
Chung Cheon 2015 \\
Total (fixed effects) \\
Total (random effects) \\
Q
\end{tabular}

DF

Significance level $R^{2}$ (inconsistency) $95 \% \mathrm{Cl}$ for $R^{2}$

\begin{tabular}{|c|c|}
\hline Intervention & Controls \\
\hline $137 / 157$ & $231 / 248$ \\
\hline $35 / 107$ & $40 / 103$ \\
\hline $52 / 134$ & $41 / 132$ \\
\hline $16 / 71$ & $27 / 88$ \\
\hline 77/216 & $115 / 203$ \\
\hline $15 / 100$ & 20/96 \\
\hline $68 / 81$ & $108 / 113$ \\
\hline $400 / 866$ & $582 / 983$ \\
\hline $400 / 866$ & $582 / 983$ \\
\hline \multicolumn{2}{|l|}{17.5208} \\
\hline \multicolumn{2}{|l|}{6} \\
\hline \multicolumn{2}{|l|}{$P=0.0075$} \\
\hline \multicolumn{2}{|l|}{$65.76 \%$} \\
\hline $23.26-84.72$ & \\
\hline
\end{tabular}

\begin{tabular}{c} 
Odds ratio \\
\hline 0.504 \\
0.766 \\
1.407 \\
0.657 \\
0.424 \\
0.671 \\
0.242 \\
0.632 \\
0.624
\end{tabular}

\begin{tabular}{c}
\hline $95 \% \mathbf{C l}$ \\
\hline $0.255-0.995$ \\
$0.435-1.348$ \\
$0.848-2.336$ \\
$0.321-1.347$ \\
$0.286-0.628$ \\
$0.321-1.402$ \\
$0.0826-0.710$ \\
$0.508-0.786$
\end{tabular}

$0.418-0.933$
$-4.114$

$-2.298$

$<0.001$

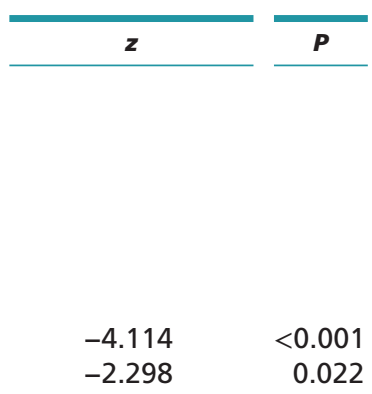

0.022

Bias indicators: Begg-Mazumdar: Kendall's Tau $=-0.142857 P=0.5619$ (low power); Egger: bias $=-0.656941$ (95\% Cl= $=-7.053883$ to 5.74$) P=0.8023$; Harbord-Egger: bias $=0.561504(92.5 \% \mathrm{Cl}=-6.312289$ to 5.189281$) P=0.8354$.

$D F$, degree of freedom; $Q$, heterogeneity in meta analysis.

\begin{tabular}{|lr}
\hline http://www.endocrineconnections.org & ○ 2017 The authors \\
DOI: 10.1530/EC-16-0110 & Published by Bioscientifica Ltd
\end{tabular}


Table $8 P$ values testing Hardy-Weinberg proportion and test for heterogeneity of studies included in the meta-analysis for FokI FF polymorphism respectively.

\begin{tabular}{l}
\hline Study \\
\hline Balazs Gyorffy 2002 \\
Tatijana Semunik 2005 \\
J J San Pedro 2005 \\
C Panierakis 2009 \\
Greear R M 2013 \\
Total (fixed effects) \\
Total (random effects) \\
Q \\
DF \\
Significance level \\
I (inconsistency) $_{95 \% \text { Cl for } R^{2}}$
\end{tabular}

\begin{tabular}{ccc}
\hline Intervention & & Controls \\
\cline { 1 - 1 } $36 / 107$ & & $29 / 103$ \\
$42 / 132$ & & $73 / 232$ \\
$31 / 71$ & & $41 / 88$ \\
$64 / 100$ & & $50 / 96$ \\
$21 / 55$ & & $28 / 50$ \\
$194 / 465$ & & $221 / 569$ \\
$194 / 465$ & & $221 / 569$ \\
6.8448 & & \\
4 & & \\
$P=0.1443$ & \\
$41.56 \%$ & \\
$0.00-78.48$ & \\
\hline
\end{tabular}

\begin{tabular}{c}
\hline Odds ratio \\
\hline 1.294 \\
1.016 \\
0.888 \\
1.636 \\
0.485 \\
1.057 \\
1.036
\end{tabular}

\begin{tabular}{|c|c|c|}
\hline $95 \% \mathrm{Cl}$ & $z$ & $\boldsymbol{P}$ \\
\hline $0.719-2.328$ & & \\
\hline $0.642-1.609$ & & \\
\hline $0.474-1.666$ & & \\
\hline $0.923-2.898$ & & \\
\hline $0.223-1.058$ & & \\
\hline $0.817-1.367$ & 0.420 & 0.675 \\
\hline $0.733-1.465$ & 0.202 & 0.840 \\
\hline
\end{tabular}

Bias indicators: Begg-Mazumdar: Kendall's Tau $=-0.6 P=0.00833$ (low power); Egger: bias $=-3.653382(95 \% \mathrm{Cl}=-14.60785$ to 7.301086$) P=0.3664$ Harbord-Egger: bias $=-3.796013(92.5 \% \mathrm{Cl}=-13.262673$ to 5.670648$) P=0.3612$.

$\mathrm{DF}$, degree of freedom; Q, heterogeneity in meta analysis.

For TagI-TT, the odds ratio ranged from 0.203 to 1.181 (Table 11). The random-effects model yielded a pooled odds ratio of 0.644 (95 percent confidence interval (CI): $0.440-0.942, P=0.023)$. There was indication of heterogeneity $(P=0.0044)$.

For TaqI-Tt, the odds ratio ranged from 0.580 to 2.983 (Table 12). The random-effects model yielded a pooled odds ratio of 1.062 (95 percent confidence interval (CI): $0.785-1.438, P=0.697)$. There was some indication of heterogeneity $(P=0.0536)$.

For TaqI-tt, the odds ratio ranged from 0.524 to 3.586 (Table 13). The fixed-effects model yielded a pooled odds ratio of 1.655 (95 percent confidence interval (CI): 1.677$2.295, P=0.001)$. There was indication of heterogeneity $(P=0.3261)$.
Forest plots are shown in Fig. 3 and B for TaqI-TT and tt alleles, respectively. Individual and pooled odds ratio estimates for the TaqI alleles are represented as squares and diamonds. In view of these estimates, there is evidence that TaqI-TT and TaqI-tt alone is associated with type 1 diabetes.

\section{Discussion}

There are a number of reports on FokI, ApaI, TaqI and BsmI polymorphisms of the VDR gene in diabetic patients, there have not been conclusive evidence that any of these polymorphisms has causative association with type 1 DM in children. In a 2006 meta-analysis that focused on

Table $9 P$ values testing Hardy-Weinberg proportion and test for heterogeneity of studies included in the meta-analysis for Fokl Ff polymorphism respectively.

\begin{tabular}{|c|c|c|c|c|c|c|}
\hline Study & Intervention & Controls & Odds ratio & $95 \% \mathrm{Cl}$ & $z$ & $\boldsymbol{P}$ \\
\hline Balazs Gyorffy 2002 & $49 / 107$ & $56 / 103$ & 0.709 & $0.412-1.221$ & & \\
\hline Tatijana Semunik 2005 & $63 / 132$ & $136 / 232$ & 0.645 & $0.419-0.991$ & & \\
\hline J J San Pedro 2005 & $35 / 71$ & $39 / 88$ & 1.222 & $0.652-2.287$ & & \\
\hline C Panierakis 2009 & $31 / 100$ & $43 / 96$ & 0.554 & $0.309-0.993$ & & \\
\hline Greear R M 2013 & $21 / 55$ & $22 / 50$ & 0.786 & $0.361-1.714$ & & \\
\hline Total (fixed effects) & $199 / 465$ & $296 / 569$ & 0.724 & $0.564-0.929$ & -2.538 & 0.011 \\
\hline Total (random effects) & $199 / 465$ & $296 / 569$ & 0.723 & $0.563-0.929$ & -2.535 & 0.011 \\
\hline $\mathrm{Q}$ & 3.8098 & & & & & \\
\hline DF & 4 & & & & & \\
\hline Significance level & $P=0.4324$ & & & & & \\
\hline$R^{2}$ (inconsistency) & $0.00 \%$ & & & & & \\
\hline $95 \% \mathrm{Cl}$ for $R^{2}$ & $0.00-79.45$ & & & & & \\
\hline
\end{tabular}

Bias indicators: Begg-Mazumdar: Kendall's Tau =-0.4 $P=0.4833$ (low power); Egger: bias =1.95378 $(95 \% \mathrm{Cl}=5.613844-9.521404) P=0.4715$; Harbord-Egger: bias $=2.01803(92.5 \% \mathrm{Cl}=-4.313428$ to 8.349488$) P=0.4557$. $\mathrm{DF}$, degree of freedom; Q, heterogeneity in meta analysis.

\begin{tabular}{|lr}
\hline http://www.endocrineconnections.org & ○ 2017 The authors \\
DOI: 10.1530/EC-16-0110 & Published by Bioscientifica Ltd
\end{tabular}

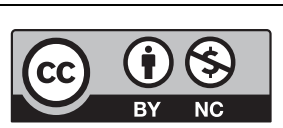

This work is licensed under a Creative Commons Attribution-NonCommercial 4.0 International License. 
Table $10 P$ values testing Hardy-Weinberg proportion and test for heterogeneity of studies included in the meta-analysis for Fokl ff polymorphism respectively.

\begin{tabular}{l}
\hline Study \\
\hline Balazs Gyorffy 2002 \\
Tatijana Semunik 2005 \\
J J San Pedro 2005 \\
C Panierakis 2009 \\
Greear R M 2013 \\
Total (fixed effects) \\
Total (random effects) \\
Q \\
DF \\
Significance level \\
P (inconsistency) \\
$95 \%$ Cl for $R^{2}$
\end{tabular}

\begin{tabular}{ccc}
\hline Intervention & & Controls \\
\cline { 1 - 1 } $22 / 107$ & & $18 / 103$ \\
$29 / 132$ & & $23 / 232$ \\
$5 / 71$ & & $8 / 88$ \\
$1 / 100$ & & $7 / 96$ \\
$7 / 55$ & $5 / 50$ \\
$64 / 465$ & & $61 / 569$ \\
$64 / 465$ & & $61 / 569$ \\
10.1246 & \\
4 & \\
$P=0.0384$ & \\
$60.49 \%$ & \\
$0.00-85.20$ & \\
\end{tabular}

\begin{tabular}{c}
\hline Odds ratio \\
\hline 1.222 \\
2.558 \\
0.758 \\
0.128 \\
1.312 \\
1.374 \\
1.159
\end{tabular}

\begin{tabular}{|c|c|c|}
\hline $95 \% \mathrm{Cl}$ & $z$ & $\boldsymbol{P}$ \\
\hline $0.612-2.441$ & & \\
\hline $1.410-4.643$ & & \\
\hline $0.237-2.426$ & & \\
\hline $0.0155-1.064$ & & \\
\hline $0.388-4.435$ & & \\
\hline $0.943-2.003$ & 1.656 & 0.098 \\
\hline $0.573-2.344$ & 0.411 & 0.681 \\
\hline
\end{tabular}

Bias indicators: Begg-Mazumdar: Kendall's Tau $=-0.6 P=0.0833$ (low power); Egger: bias $=-3.173487(95 \% \mathrm{Cl}=-6.536026$ to 0.189052$) P=0.575$; Harbord-Egger: bias $=-4.109035(92.5 \% \mathrm{Cl}=-8.5417147$ to 0.323644$) P=0.0889$.

DF, degree of freedom; Q, heterogeneity in meta analysis.

VDR polymorphisms, FokI, ApaI, TaqI, BsmI and type 1 DM association included mainly adult samples and did not reveal any specific association (25). However, out of 19 published papers included in this meta-analysis, authors of only five papers specifically looked for the presence of autoantibodies to distinguish type 1 diabetes from type 2 . In other 14 studies included in this metaanalysis, investigators used only one criteria (e.g., ketosis, early requirement of insulin). This may be one of the main reasons for different statistical results other than ethnic diversities when compared to our results. DM1 is mainly a disease of pediatric age: considering the qualitative assessment of study inclusion criteria, choosing studies where diagnosis is at pediatric age with age matching control samples, and/or taking American Diabetes Association criteria would end up with more reliable meta-analysis results. In our study, mean age of control samples are in pediatric range. In another meta-analysis involving Chinese adult samples, authors concluded that BsmI polymorphisms in the VDR region would increase the risk of type $1 \mathrm{DM}$ in East Asians (26). In the study of Zhang J, Asian samples with BsmI polymorphism was found to have a significant association with increased risk of type 1 DM (27). The study of Qin WH demonstrated a significant relationship among BsmI $B$ allele and $\mathrm{BB}$ genotype and increased risk for type 1 DM in Asians, whereas this study included Latino and African adult samples and authors also found another

Table $11 P$ values testing Hardy-Weinberg proportion and test for heterogeneity of studies included in the meta-analysis for TaqITT polymorphism respectively.

\begin{tabular}{|c|c|c|c|c|c|c|}
\hline Study & Intervention & Controls & Odds ratio & $95 \% \mathrm{Cl}$ & $z$ & $\boldsymbol{P}$ \\
\hline Chang 2000 & $142 / 157$ & $233 / 248$ & 0.609 & $0.289-1.284$ & & \\
\hline Balazs Gyorffy 2002 & 44/107 & $42 / 103$ & 1.014 & $0.585-1.759$ & & \\
\hline Vaselin Scrabic 2003 & $54 / 134$ & $48 / 132$ & 1.181 & $0.720-1.938$ & & \\
\hline J J San Pedro 2005 & 24/71 & $31 / 88$ & 0.939 & $0.486-1.813$ & & \\
\hline Diego Garcia 2007 & $115 / 216$ & $121 / 203$ & 0.772 & $0.524-1.137$ & & \\
\hline C Panierakis 2009 & $10 / 100$ & $34 / 96$ & 0.203 & $0.0933-0.440$ & & \\
\hline Greear R M 2013 & $18 / 55$ & $26 / 50$ & 0.449 & $0.204-0.990$ & & \\
\hline Chung Cheon 2015 & $66 / 81$ & $105 / 113$ & 0.335 & $0.135-0.834$ & & \\
\hline Total (fixed effects) & $473 / 921$ & $640 / 1033$ & 0.713 & $0.580-0.876$ & -3.213 & 0.001 \\
\hline Total (random effects) & $473 / 921$ & $640 / 1033$ & 0.644 & $0.440-0.942$ & -2.270 & 0.023 \\
\hline Q & 20.6282 & & & & & \\
\hline DF & 7 & & & & & \\
\hline Significance level & $P=0.0044$ & & & & & \\
\hline$R^{2}$ (inconsistency) & $66.07 \%$ & & & & & \\
\hline $95 \% \mathrm{Cl}$ for $R^{2}$ & $28.03-84.00$ & & & & & \\
\hline
\end{tabular}

Bias indicators: Begg-Mazumdar: Kendall's Tau $=-0.642857 P=0.0141$ (low power); Egger: bias $=-3.773452(95 \% \mathrm{Cl}=-8.197852$ to 0.650947$) P=0.0819$; Harbord-Egger: bias $=-3.522136(92.5 \% \mathrm{Cl}=-8.048273$ to 1.004$) P=0.1452$

DF, degree of freedom; Q, heterogeneity in meta analysis.

\begin{tabular}{lr}
\hline http://www.endocrineconnections.org & ○ 2017 The authors \\
DOI: $10.1530 /$ EC-16-0110 & Published by Bioscientifica Ltd
\end{tabular}


Table $12 P$ values testing Hardy-Weinberg proportion and test for heterogeneity of studies included in the meta-analysis for TaqITt polymorphism respectively.

\begin{tabular}{l} 
Study \\
\hline Chang 2000 \\
Balazs Gyorffy 2002 \\
Vaselin Scrabic 2003 \\
J J San Pedro 2005 \\
Diego Garcia 2007 \\
C Panierakis 2009 \\
Greear R M 2013 \\
Chung Cheon 2015 \\
Total (fixed effects) \\
Total (random effects) \\
Q \\
DF \\
Significance level \\
$I^{2}$ (inconsistency) \\
$95 \%$ Cl for ${ }^{2}$ \\
\hline
\end{tabular}

\begin{tabular}{ccc}
\hline Intervention & & Controls \\
\cline { 1 - 1 } $15 / 157$ & & $14 / 248$ \\
$28 / 107$ & & $33 / 103$ \\
$55 / 134$ & & $72 / 132$ \\
$36 / 71$ & & $43 / 88$ \\
$79 / 216$ & $69 / 203$ \\
$64 / 100$ & & $59 / 96$ \\
$26 / 55$ & & $24 / 50$ \\
$15 / 81$ & & $8 / 113$ \\
$318 / 921$ & $322 / 1033$ \\
$318 / 921$ & $322 / 1033$ \\
13.8658 & \\
7 & \\
$P=0.0536$ & \\
$49.52 \%$ & \\
$0.00-77.47$ & \\
\hline
\end{tabular}

\begin{tabular}{c}
\hline Odds ratio \\
\hline 1.766 \\
0.752 \\
0.580 \\
1.076 \\
1.120 \\
1.115 \\
0.971 \\
2.983 \\
1.017 \\
1.062 \\
\end{tabular}

\begin{tabular}{|c|c|c|}
\hline $95 \% \mathrm{Cl}$ & $z$ & $\boldsymbol{P}$ \\
\hline $0.828-3.766$ & & \\
\hline $0.414-1.367$ & & \\
\hline $0.357-0.943$ & & \\
\hline $0.576-2.012$ & & \\
\hline $0.750-1.673$ & & \\
\hline $0.625-1.990$ & & \\
\hline $0.451-2.091$ & & \\
\hline $1.199-7.423$ & & \\
\hline 0.829-1.248 & 0.165 & 0.869 \\
\hline $0.785-1.438$ & 0.390 & 0.697 \\
\hline
\end{tabular}

Bias indicators: Begg-Mazumdar: Kendall's Tau=0.047619 $P>0.9999$ (low power); Egger: bias $=1.307065(95 \% \mathrm{Cl}=-4.196619$ to 6.810748$) P=0.5682$; Harbord-Egger: bias $=1.410342(92.5 \% \mathrm{Cl}=-3.284733$ to 6.105417$) P=0.5305$.

$\mathrm{DF}$, degree of freedom; Q, heterogeneity in meta analysis.

specific association with BsmIbb genotype and type 1 DM in overall populations (28). The novel finding in our study was the presence of an increased risk of type $1 \mathrm{DM}$ in carriers of BsmIBB, BsmIBb and TaqItt polymorphisms and decreased risk of type $1 \mathrm{DM}$ in children with BsmIbb and TaqITT polymorphisms. There are GWAS studies that widen our approach to vitamin D receptor polymorphisms and DM1.

Meta-analysis may be more reliable when evaluating genotype frequencies in certain diseases because in a way it may reduce the effect of biased sampling or nonrandom mating in individual study population. Results of studies so far, regarding VDR polymorphisms and DM1 susceptibility, are conflicting. In the study of Garcia and coworkers, an association was found between BsmI polymorphism and DM1 (15). The frequency of genotype bb was found to be significantly lower in the cases than that in controls. Among five prevalent haplotypes, BAT has been found to be statistically more frequent in study group in the same study. Among genotype combinations, AabbTT was found to be higher in controls. In our study population, genotype combination frequencies were not

Table $13 P$ values testing Hardy-Weinberg proportion and test for heterogeneity of studies included in the meta-analysis for Taqltt polymorphism respectively.

\begin{tabular}{|c|c|c|c|c|c|c|}
\hline Study & Intervention & Controls & Odds ratio & $95 \% \mathrm{Cl}$ & $z$ & $\boldsymbol{P}$ \\
\hline T J Chang 2000 & $0 / 157$ & $1 / 248$ & 0.524 & $0.0212-12.939$ & & \\
\hline Balazs Gyorffy 2002 & $33 / 107$ & $26 / 103$ & 1.321 & $0.721-2.418$ & & \\
\hline Vaselin Scrabic 2003 & $25 / 134$ & $11 / 132$ & 2.523 & $1.186-5.367$ & & \\
\hline J J San Pedro 2005 & 11/71 & $14 / 88$ & 0.969 & $0.410-2.290$ & & \\
\hline Diego Garcia 2007 & $22 / 216$ & $13 / 203$ & 1.657 & $0.811-3.386$ & & \\
\hline C Panierakis 2009 & $22 / 100$ & 7/96 & 3.586 & $1.453-8.849$ & & \\
\hline Greear R M 2013 & $6 / 55$ & $5 / 50$ & 1.102 & $0.314-3.862$ & & \\
\hline Chung Cheon 2015 & $0 / 81$ & $0 / 113$ & - & & & \\
\hline Total (fixed effects) & $119 / 921$ & $77 / 1033$ & 1.677 & $1.225-2.295$ & 3.230 & 0.001 \\
\hline Total (random effects) & $119 / 921$ & $77 / 1033$ & 1.655 & $1.163-2.356$ & 2.798 & 0.005 \\
\hline Q & 6.9433 & & & & & \\
\hline DF & 6 & & & & & \\
\hline Significance level & $P=0.3261$ & & & & & \\
\hline$R^{2}$ (inconsistency) & $13.59 \%$ & & & & & \\
\hline $95 \% \mathrm{Cl}$ for $R^{2}$ & $0.00-75.19$ & & & & & \\
\hline
\end{tabular}

Bias indicators: Begg-Mazumdar: Kendall's Tau $=-0.047619 P>0.9999$ (low power); Egger: bias $=-6.680722(95 \% \mathrm{Cl}=-3.88097$ to 2.519525$) P=0.608$; Harbord-Egger: bias $=-1.122847(92.5 \% \mathrm{Cl}=-3.907446$ to 1.661601$) P=0.4074$.

DF, degree of freedom; Q, heterogeneity in meta analysis.

\begin{tabular}{|lr}
\hline http://www.endocrineconnections.org & ○ 2017 The authors \\
DOI: 10.1530/EC-16-0110 & Published by Bioscientifica Ltd
\end{tabular}

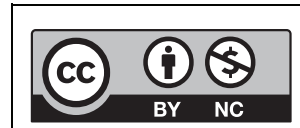

This work is licensed under a Creative Commons Attribution-NonCommercial 4.0 International License. 

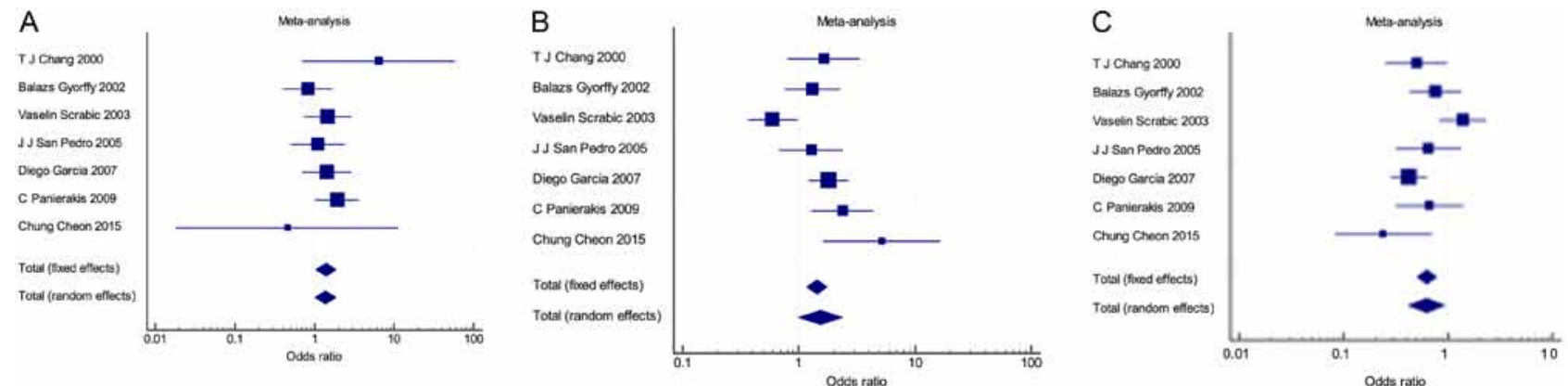

Figure 2

(A, B and C) Forest plots showing individual and pooled odds ratio estimates of $B s m / B B, B s m / B b, B s m l b b$ polymorphisms, respectively.

assessed because of unavailable data, and this may be one of the limitations of our study.

In the study of San-Pedro JI, an association of an haplotype ' $\mathrm{fBAt}^{\prime}$ ' and risk of type $1 \mathrm{DM}$ in Basque population has been identified (16). In the study of Skrabic V, BBAAtt genotype combination was found to be associated with type $1 \mathrm{DM}$ in Dalmatian population of southern Croatia, with the ' $\mathrm{tt}$ ' genotype preferentially presented in the affected individuals (17). This was also noticed in previous studies that focused on association of VDR gene polymorphisms with increased susceptibility to T1DM in Taiwanese, Japanese, South Asian (Indian) and German populations $(29,30,31,32)$. TaqI polymorphism among type $1 \mathrm{DM}$ patients and control subjects differed significantly, with the VDR tt genotype occurring more frequently in T1DM patients. No difference was noticed in the genotype frequencies of BsmI and ApaI polymorphisms in cases and controls. We evaluated TaqItt polymorphism frequency and demonstrated a significant increase in diabetic children in our study. In the study of Zemunik and coworkers, some evidence of association of Tru91-BsmI haplotype and type $1 \mathrm{DM}$ in population of South Croatia was found (17). In our meta-analysis, we have included two studies from Croatia. One of the limitations of this study was that its sample size was small, it only included nine studies and the power of this study is not high. In the study of Panierakis and coworkers, homogeneous southern European population with low incidence of type $1 \mathrm{DM}$ was included in the study group, and they found an association of T1DM and FokI, BsmI, ApaI and TaqI polymorphisms. In this study, FokIFF genotype and $\mathrm{F}$ allele and BsmIBB genotype and B allele were less frequent in individuals with T1DM (21). In the same study, ApaIAA genotype and A allele, as well as TaqITT genotype and $\mathrm{T}$ allele were more frequent in individuals. Greear and coworkers also studied the association of Taq1, Fok1, Apa 1 and type $1 \mathrm{DM}$ and found no significant difference in distribution of VDR polymorphisms in diabetic patients, whereas diabetic patients had significantly decreased levels of vitamin D levels than healthy controls (22). In the study of Cheon $\mathrm{CK}$ and coworkers, the frequency of $\mathrm{bb}$ and TT genotype has been found to be significantly
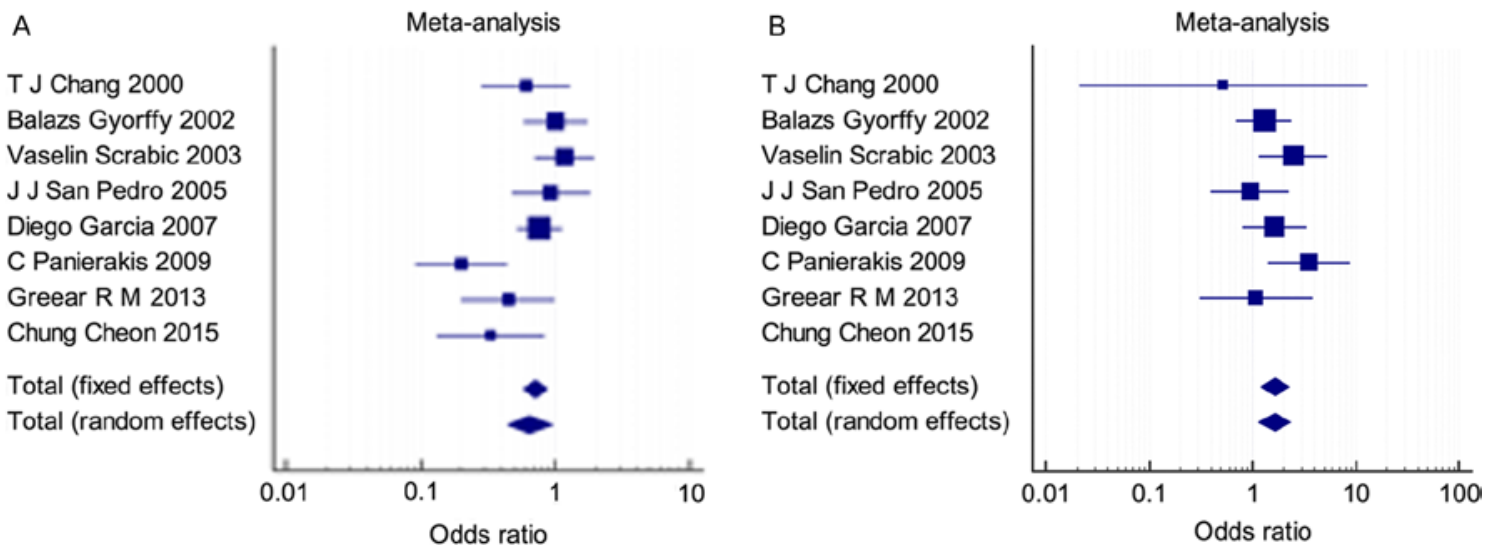

Figure 3

(A and B) Forest plots showing individual and pooled odds ratios of TaqITT and Taqltt polymorphisms, respectively.

$$
\begin{array}{lr}
\text { http://www.endocrineconnections.org } & \text { ( } 2017 \text { The authors } \\
\text { DOI: } 10.1530 / E C-16-0110 & \text { Published by Bioscientifica Ltd }
\end{array}
$$


increased among carriers demonstrating a protective effect in Korean subjects (23). Gyorffy and coworkers suggested a strong linkage disequilibrium between the ' $b$ ' and ' $a$ ' alleles in his study. The close loci of these polymorphisms might be an explanation for the stability of linkage, but the background of these combinations need further investigation (19). In the same study, a strong association has been found between carrier state of the ' $b$ ' $+{ }^{\prime} a{ }^{\prime}+{ }^{\prime} u$ ' alleles and the presence of type $1 \mathrm{DM}$ in females. There are other reports as well that point out to a gender-specific association and consequence of gene polymorphism (33). A number of studies have shown that patients with $1 \mathrm{DM}$ have low levels of vitamin D although other studies have conflicting results $(34,35,36)$. In 2010, GWAS study in approximately 30,000 individuals from European descent identifies variants at four loci that were associated with 25(OH)D levels: GC rs2282679, dhcr7 RS 12785878 and CYP2R1 (37). A second GWAS of 25(OH)D levels confirmed the findings with GC, DHCR7 and CYP2R1 (38). These variants are located within or near genes involved in vitamin D transport (GC), cholesterol synthesis (DHCR7) and hydroxylation (CYP2R1 and CTP24A1) (37). Cooper and coworkers recently tested genetic variants influencing 25(OH)D metabolism for an association with both circulating 25(OH)D metabolism for an association with both circulating 25(OH)D concentrations and T1D. They replicated the associations found in the GWAS of the four vitamin D metabolism genes (GC, DHCR7, CYP2R1 and CYP24A1) with 25(OH)D in control subjects and found that CYP27B1, DHCR7 and CYP2R1 were associated with type 1 diabetes (39). The Fok1 polymorphism of the VDR, which increases the transcriptional activity of VDR, has been suggested as an influencing factor for susceptibility to T1DM. It affects insulin secretion and sensitivity and has been found to be a susceptibility factor for the development of diabetic retinopathy $(40,41)$. In addition, vitamin D-binding protein gene polymorphisms were found to be associated with diabetes-associated antibody insulinoma antigen 2 and with T1DM (42). In the study of Greear and coworkers, low vitamin D levels in the diabetic children have been attributed to inflammatory or other pathologic processes, mainly as a consequence of the disease rather than being a risk factor, as previously stated in DAISY study (43). In the study of Chang and coworkers, the allele frequency of the BsmI differed between Taiwanese patients and controls significantly (20). There are some limitations in this meta-analysis. The power of this study should further be increased by additional studies, and this meta-analysis involves only nine studies. Some of the studies contained small number of cases, and background of the patients varied across included studies. However our meta-analysis employed a random-effects model designed to encounter these variations and found significant effect of polymorphisms on type 1 DM susceptibility.

As a conclusion, our meta-analysis of accessible published data has demonstrated statistically significant association between BsmIBB, BsmIBb, BsmIbb, TaqITT and Taqtt polymorphisms and susceptibility to type 1 DM in children; however, influence of vitamin D receptor gene polymorphisms on susceptibility to type 1 diabetes deserves further investigations. Meta-analysis includes larger data sets and accordingly may demonstrate more reliable statistical results to rule out genotype-phenotype correlations of diseases.

\section{Declaration of interest}

The authors declare that there is no conflict of interest that could be perceived as prejudicing the impartiality of the research reported.

\section{Funding}

This work did not receive any specific grant from any funding agency in the public, commercial, or not-for-profit sector.

\section{References}

1 Todd JA, Bell JI \& McDevitt HO. HLA DQ beta gene contributes to susceptibility and resistence to insulin dependent diabetes mellitus. Nature 1987329 599-604. (doi:10.1038/329599a0)

2 Ban Y, Taniyama M, Yanagawa T, Yamada S, Maruyama T, Kasuga A \& Ban Y. Vitamin D receptor initiation codon polymorphism influences susceptibility to type 1 dibetes mellitus in Japanese population. BMC Medical Genetics 20012 7-13. (doi:10.1186/1471-2350-2-7)

3 Lemire JM, Adams JS, Sakai R \& Jordan SC. 1alpha,25Dihydroxyvitamin D3 suppresses proliferation and immunoglobulin production by normal human peripheral blood mononuclear cells. Journal of Clinical Investigation 198474 657-661. (doi:10.1172/ JCI111465)

4 Yang S, Smith C, Prahl JM, Luo X \& DeLuca HF. Vitamin D deficiency suppresses cell-mediated immunity in vivo. Archives of Biochemistry and Biophysics 1993 198-106. (doi:10.1006/abbi.1993.1260)

5 Pugliese A. Genetics of type 1 diabetes. Endocrinology and Metabolism Clinics of North America 200433 1-16. (doi:10.1016/S08898529(03)00082-3)

6 Vyse TJ \& Todd JA. Genetic analysis of autoimmune disease. Cell 1996 85 311-318. (doi:10.1016/S0092-8674(00)81110-1)

7 McDermott MF, Ramachandran A, Ogunkolade BW, Aganna E, Curtis D, Boucher BJ, Snehalatha C \& Hitman GA. Allelic variation in the vitamin D receptor influences susceptibility to IDDM in Indian Asians. Diabetologia 19978 971-975. (doi:10.1007/s001250050776)

8 Motohashi Y, Yamada S \& Yanagawa T. Vitamin D receptor gene polymorphism affects onset pattern of type 1 diabetes. Journal of Clinical Endocrinology and Metabolism 200388 3137-3140. (doi:10.1210/jc.2002-021881)

9 Turpeinen H, Hermann R, Vaara S, Laine AP, Simell O, Knip M, Veijola R \& Ilonen J. Vitamin D receptor polymorphisms: no association with type 1 diabetes in the Finnish population. European Journal of Endocrinology 20036 591-596. (doi:10.1530/eje.0.1490591)

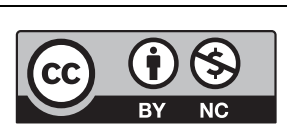

This work is licensed under a Creative Commons Attribution-NonCommercial 4.0 International License. 
10 Lemos MC, Fagulha A, Coutinho E, Gomes L, Bastos M, Barros L, Carrilho F, Geraldes E, Regateiro FJ \& Carvalheiro M. Lack of association of vitamin D receptor polymorphisms with susceptibility to type 1 diabetes mellitus in the Portugeese polpulation. Human Immunology 20082 134-138. (doi:10.1016/j.humimm.2008.01.008)

11 Obi-Tabot ET, Tian XQ, Chen TC \& Holick MF. A human skin equivalent model that mimics the photoproduction of vitamin D3 in human skin. In Vitro Cellular and Developmental Biology 20003 201-204. (doi:10.1290/1071-2690(2000)036<0201:AHSEMT $>2.0 . \mathrm{CO} ; 2)$

12 San-Pedro JI, Bilbao JR \& Perez de Nanclares G. Heterogeneity of vitamin $\mathrm{D}$ receptor gene association with celiac disease and type1 diabetes mellitus, Autoimmunity 200538 439-444. (doi:10.1080/08916930500288455)

13 Nejentsev S, Cooper JD, Godfrey L, Howson JM, Rance H, Nutland S, Walker NM, Guja C, Ionescu-Tirgovişte C, Savage DA, et al. Analysis of the vitamin $\mathrm{D}$ receptor gene sequence variants in type 1 diabetes. Diabetes 200410 641-642.

14 DerSimonian R \& Laird N. Meta-analysis in clinical trials. Controlled Clinical Trials 19863 177-188. (doi:10.1016/0197-2456(86)90046-2)

15 Garcia D, Angel B, Carrasco E, Albala C, Santos JL \& Pérez-Bravo F. VDR polymorphisms influence the immune response in type 1 diabetic children from Santiago, Chile. Diabetes Research and Clinical Practice 20071 134-140. (doi:10.1016/j.diabres.2006.10.018)

16 San Pedro JI, Bilbao JR, Perez de Nanclares G, Vitoria JC, Martul P $\&$ Castaño L.Heterogeneity of vitamin D receptor gene association with celiac disease and type 1 diabetes mellitus. Autoimmunity 20056 439-444. (doi:10.1080/08916930500288455)

17 Zemunik T, Scrabic V, Boraska V, Diklic D, Terzic IM, Capkun V, Peruzovic M \& Terzic J. FokI polymorphism, vitamin D receptor, and interleukin-1 receptor haplotypes are associated with type 1 diabetes in the dalmatian population. Journal of Molecular Diagnostics 20055 600-604. (doi:10.1016/S1525-1578(10)60593-4)

18 Skrabic V, Zemunik T, Situm M \& Terzić J. Vitamin D receptor polymorphism and susceptibility to type 1 diabetes in the Dalmatian population. Diabetes Research and Clinical Practice 2003 131-35. (doi:10.1016/S0168-8227(02)00195-X)

19 Gyorffy B, Vasarhelyi B, Krikovszky D, Madácsy L, Tordai A, Tulassay T \& Szabó A. Gender-spesific association of vitamin D receptor polymorphism combinations with type 1 diabetes mellitus. European Journal of Endocrinology 20026 803-808. (doi:10.1530/ eje.0.1470803)

20 Chang TJ, Lei HH, Yeh JI, Chiu KC, Lee KC, Chen MC, Tai TY \& Chuang LM. Vitamin D receptor gene polymorphisms influence susceptibility to type 1 diabetes mellitus in the Taiwanese population. Clinical Endocrinology 20005 575-580. (doi:10.1046/j.13652265.2000.00985.x)

21 Panierakis C, Goulielmos G, Mamoulakis D, Petraki E, Papavasiliou E \& Galanakis E. Vitamin D receptor gene polymorphisms and susceptibility to type 1 diabetes in Crete, Greece. Clinical Immunology 20092 276-281. (doi:10.1016/j.clim.2009.08.004)

22 Greear RM, Portelli SL, Hung BS, Cleghorn GJ, McMahon SK, Batch JA \& Conwell LS. Serum vitamin D levels are lower in Australian children and adolescents with type 1 diabetes than in children without diabetes. Pediatric Diabetes 20131 31-41. (doi:10.1111/ j.1399-5448.2012.00890.x)

23 Cheon CK, Nam HK, Lee KH, Kim SY, Song JS \& Kim C. Vitamin D receptor gene polymorphisms and type 1 diabetes mellitus in a Korean population. Pediatrics International 20155 870-874. (doi:10.1111/ped.12634)

24 American Diabetes Association. Diagnosis and classification of diabetes mellitus. Diabetes Care 201033 (Supplement) 62S-69S. (doi:10.2337/dc11-s062)

25 Guo SW, Magnuson VL, Schiller JJ, Wang X, Wu Y \& Ghosh S. Metaanalysis of vitamin $\mathrm{D}$ receptor polymorphisms and type 1 diabetes: a HuGE Review of Genetic Association Studies. American Journal of Epidemiology 20068 711-724. (doi:10.1093/aje/kwj278)

26 Wang Q, Xi B, Reilly KH, Liu M \& Fu M. Quantitative assessment of the associations between four polymorphisms (FokI, ApaI, BsmaI, TaqI) of vitamin D receptor gene and risk of diabetes mellitus. Molecular Biology Reports 201210 9405-9414. (doi:10.1007/s11033012-1805-7)

27 Zhang J, Li W, Liu J, Wu W, Ouyang H, Zhang Q, Wang Y, Liu L, Yang R, Liu X, et al. Polymorphisms in the vitamin D receptor gene and type 1 diabetes mellitus risk: an update by meta-analysis. Molecular and Cellular Endocrinology 20121 135-142. (doi:10.1016/j. mce.2012.02.003)

28 Qin WH, Wang XH, Qiu LJ, Huang XB, Huang Y, Wu NR \& Liang HS. A meta-analysis of association of vitamin $\mathrm{D}$ receptor BsmI gene polymorphisms with the risk of type 1 diabetes mellitus. Journal of Receptor and Signal Transduction Research 20145 372-377. (doi:10.3109 /10799893.2014.903420)

29 Yokota I, Satomura S, Kitamura S, Taki Y, Naito E, Ito M, Nisisho K \& Kuroda Y. Association between vitamin D receptor genotype and age of onset in juvenile Japanese patients with type 1 diabetes. Diabetes Care 20027 1244. (doi:10.2337/diacare.25.7.1244)

30 McDermott MF, Ramachandran A, Ogunkolde BW, Aganna E, Curtis D, Boucher BJ, Snehalatha C \& Hitman GA. Allelic variations in the vitamin D receptor influences susceptibility to IDDM in Indian Asians. Diabetologia 19978 971-975. (doi:10.1007/s001250050776)

31 Pani MA, Knapp M, Donner H, Braun J, Baur MP, Usadel KH \& Badenhoop K. Vitamin D receptor allele combinations influence genetic susceptibility to type I Diabetes in Germans. Diabetes 20003 504-507. (doi:10.2337/diabetes.49.3.504)

32 Ban Y, Taniyama M, Yanagawa T, Yamada S, Maruyama T, Kasuga A \& Ban Y. Vitamin D receptor initiation codon polymorphism influences genetic susceptibility to type 1 diabetes mellitus in the Japanese population. BMC Medical Genetics 20017 2-7.

33 Kitagawa I, Kitagawa Y, Kawase Y, Nagaya T \& Tokudome S. Advanced onset of menarche and higher bone mineral density depending on itamin D receptor gene polymorphism. European Journal of Endocrinology 1998139 522-527. (doi:10.1530/eje.0.1390522)

34 Baumgartl HJ, Standl E, Schmidt-Gayk H, Kolb HJ, Janka HU \& Ziegler AG. Changes of vitamin D3 serum concentrations at the onset of immune-mediated type 1 (insulin dependent) diabetes mellitus. Diabetes Research 199116 145-148.

35 Holick MF. Vitamin D: importance in the prevention of cancers, type 1 diabetes, heart disease and osteoporosis. American Journal of Clinical Nutrition 200437 680-683.

36 Pozzili P, Manfrini S, Crino A, Picardi A, Leomanni C, Cherubini V, Valente L, Khazrai M, Visalli N \& IMDIAB Group. Low levels of 25-hydroxyvitamin D3 and 1,25-dihydroxyvitamin D3 in patients with nely diagnosed type 1 diabetes. Hormone and Metabolic Research 20053 680-683. (doi:10.1055/s-2005-870578)

37 Wang TJ, Zhang F, Richards JB, Kestenbaum B, van Meurs JB, Berry D, Kiel DP, Streeten EA, Ohlsson C, Koller DL, et al. Common genetic determinants of vitamin D insufficiency: a genome-wide association study. Lancet 2010376 180-188. (doi:10.1016/S0140-6736(10)60588-0)

38 Ahn J, Yu K, Stolzenberg-Solomon R, Simon KC, McCullough ML, Gallicchio L, Jacobs EJ, Ascherio A, Helzlsouer K, Jacobs KB, et al. Genome-wide association study of circulating vitamin D levels. Human Molecular Genetics 201019 2739-2745. (doi:10.1093/hmg/ ddq155)

39 Cooper JD, Smyth DJ, Walker NM, Stevens H, Burren OS, Wallace C, Greissl C, Ramos-Lopez E, Hyppönen E, Dunger DB, et al. Inherited variation in vitamin $\mathrm{D}$ genes is associated with predisposition to autoimmune disease type 1 diabetes. Diabetes 201160 1624-1631. (doi:10.2337/db10-1656)

40 Taverna MJ, Selam JL \& Slama G. Association between a protein polymorphism in the start codon of the vitamin $\mathrm{D}$ receptor gene and

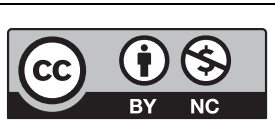

This work is licensed under a Creative Commons Attribution-NonCommercial 4.0 International License. 
severe diabetic retinopathy in C-peptide-negative type 1 diabetes. Journal of Clinical Endocrinology and Metabolism $2005904803-4808$. (doi:10.1210/jc.2004-2407)

41 Taverna MJ, Sola A, Guyot-Argenton C, Pacher N, Bruzzo F, Slama G, Reach G \& Selam JL. TaqI polymorphism of the vitamin D receptor and risk of severe diabetic retinopathy. Diabetologia $200245436-442$. (doi:10.1007/s00125-001-0769-2)

42 Ongagna JC, Pinget M \& Belcourt A. Vitamin D-binding protein gene polymorphism association with IA-2 utoantibodies in type
1 diabetes. Clinical Biochemistry 200538 415-419. (doi:10.1016/j. clinbiochem.2004.12.013)

43 Simpson M, Brady H, Yin X, Seifert J, Barriga K, Hoffman M, Bugawan T, Barón AE, Sokol RJ, Eisenbarth G, et al. No association of vitamin D intake or 25-hydroxyvitamin D levels in childhood with risk of islet autoimmunity and type 1 diabetes: the Daibetes Autoimmunity Study in the Young (DAISY). Diabetologia 201154 2779-2788. (doi:10.1007/ s00125-011-2278-2)

Received in final form 13 February 2017

Accepted 23 February 2017

Accepted Preprint published online 23 February 2017
This work is licensed under a Creative Commons Attribution-NonCommercial 4.0 International License. 